\title{
For Tim Thornton
}


Susan M. Johns - 9781526137555

Downloaded from manchesterhive.com at 04/26/2023 02:52:36PM 